\title{
TESES DE DOUTORADO E DISSERTAÇÕES DE MESTRADO
}


366 


\title{
A LIBERDADE DE CONCORRÊNCIA COMO A QUINTA LIBERDADE FUNDAMENTAL: CONTRIBUIÇÃO PARA UM MERCADO COMUM DO SUL ${ }^{1}$
}

\section{AUGUSTO JAEGER JÚNIOR}

\author{
Data da defesa 4-04-2005
}

\section{RESUMO}

A presente tese examina a contribuição da liberdade de concorrência para o estabelecimento da fase de mercado comum na Comunidade Européia, tendo como objetivo propor alternativas para o Mercosul regulamentá-la e assim possibilitar o alcance do seu verdadeiro mercado comum. O primeiro capítulo retrata as etapas que a Comunidade superou desde o seu surgimento até o estabelecimento do mercado comum e confirma que a evolução do processo, que envolveu um novo objetivo, o mercado interno, e a importância que para tanto assumiu o direito comunitário da concorrência, presente já nos Tratados constitutivos e tutelador da liberdade de concorrência, determinaram a essa uma nova classificação, qual seja a de quinta liberdade fundamental, o que foi comprovado com entendimentos doutrinários e esforços jurisprudenciais. O segundo capítulo centra-se nas reformas no direito comunitário da concorrência e nas suas contribuições para a aproximação do sistema da concorrência com o sistema das liberdades fundamentais, para a manutenção do mercado interno na Comunidade Européia e para o desenvolvimento do direito da concorrência em outros processos de integração, bem como no estudo de propostas de regulamentações de ordem internacional do direito da concorrêncía. (Continua) Nota resumo (Continuação) No âmbito comunitário, foram consideradas a refoma ocorrida nas regras de aplicação dos artigos 81 e 82 TCE, com o Regulamento n. 1/2003, a acontecida nas regras do controle das concentrações de empresas, com o Regulamento $n$. 139/2004, e as mudanças nas regras aplicáveis aos Estados-membros, como, por exemplo, as trazidas pelos Regulamentos ns. 994/98 e 659/99. No âmbito internacional, recebeu atençāo o Draft of International Antitrust Code, sugerido à $\mathrm{OMC}$. $\mathrm{O}$ terceiro capítulo apresenta os objetivos alcançados e os nãoalcançados desde o surgimento do processo de integração do Mercosul e o estágio em que ele atualmente se encontra. O estudo caracterizou o presente momento como o apropriado para o processo confirmar o seu desejo de alcançar a etapa de mercado comum, o que deverá ocorrer com a implantação de um 
eficaz direito da concorrência e com a conformação das demais liberdades fundamentais. (Continua) Nota resumo (Continuação) As conclusões são que a liberdade de concorrência é a quinta liberdade econômica fundamental dos processos de integração que tenham por objetivo alcançar um mercado comum, que as reformas sofridas pelo direito comunitário da concorrência estão em sintonia com essa visão e que oferecem um aval ao sistema previsto para o Mercosul. Além disso, que a garantia da liberdade de concorrência integrou os mercados nacionais e contribuiu para que a Comunidade atingisse o mercado comum e que a visão da liberdade de concorrência como a quinta liberdade fundamental e como permitidora do seu alcance na Comunidade contribui para o estabelecimento de um direito da concorrência e este para o alcance de um verdadeiro mercado comum pelo Mercosul.

1 A banca foi composta pelos Professores Doutores: Erik fayme, Professor da Universidade de Heideiberg, e Doutor em Direito pela Universidade de Munique, Alemanha; Joäo Grandino Rodas, Professor da Universidade de São Paulo Doutor em Direito pela mesma Universidade; Luiz Otávio Pimentel, Professor da Universidade Federal de Santa Catarina e Doutor em Direito pela Universidade de Barcelona, Espanha; Gustavo Tepedino, Professor da Universidade Estadual do Rio de Janeiro e Doutor em Direito pela Universidade de Camerino, Itália; José Alcebfades de Oliveira Júnior, Professor da Universidade Federal do Rio Grande do Sul e Doutor em Direito pela Universidade Federal de Santa Catarina. A referida defesa foi presidida pela Professora Doutora Cláudia Lima Małques, Professora Titular da Universidade Federal do Rio Grande do Sul e Doutora em Direito pela Universidade de Heidelberg - Alemanha, orientadora do referido trabalho. 


\section{FIDÚCIA - UMA ANÁLISE DOS NEGÓCIOS \\ FIDUCIÁRIOS A PARTIR DE SUAS RELAÇÕES EXTERNAS ${ }^{1}$}

\section{CHRISTOPH FABIAN}

Data da defesa: 31-05-2005

\section{RESUMO}

Este trabalho procura analisar um aspecto dos negócios fiduciários: as relaçōes jurídicas obtidas pelo fiduciante ou pelo fiduciário com terceiros. Em primeiro passo descreve o negócio fiduciário e as suas formas previstas no direito positivo. Em seguida, busca avaliar relações externas como no caso da alienação da coisa ou da interferência processual por terceiros na falência ou na execução civil.

A banca foi composta pelos Professores Doutores: Michael R. Will, Professor da Universidade de Genebra, Suíça, e Doutor em Direito pela Universidade de Munique, Alemanha; Carlos Alberto Ghersi, da Universidad de Buenos Aires, Argentina, e Doutor em Direito pela mesma Universidade; José Antônio Peres Gediel, Professor da Universidade Federal do Paraná e Doutor em Direito pela mesma Universidade; Véra Maria lacob de Fradera, Professora da Universidade Federal do Rio Grande do Sul e Doutora em Direito pela Universite De Paris II, França; Carlos Klein Zanini, Professor da Universidade Federal do Rio Grande do Sul e Doutor em Direito pela Universidade de São Paulo. A referida defesa foi presidida pela Professora Doutora Cláudia Lima Marques, Professora Titular da Universidade Federal do Rio Grande do Sul e Doutora em Direito pela Universidade de Heidelberg - Alemanha, orientadora do referido trabaho. 


\section{INSTITUIÇÕES DE ASSISTÊNCIA SOCIAL E IMUNIDADE TRIBUTÁRIA ${ }^{1}$}

\section{ANDREA NÁRRIMAN CEZNE}

\section{Data da defesa: 26-09-2005}

\section{RESUMO}

A problemática do presente trabalho é a análise da configuração atual da Assistência Social e suas instituições no Brasil, investigando o desenvolvimento do setor e a natureza da atividade assistencial, a partir da Constituição Federal de 1988. O objetivo principal desse trabalho é analisar as desonerações tributárias referentes à assistência social e sua regulação, especificamente a questão da imunidade tributária prevista pela Constituiçāo Federal de 1988 (no artigo 150, VI, "C"). A metodologia utilizada foi a interpretativa, através de estudo de casos e análise teórica, buscando partir das decisōes do Supremo Tribunal Federal para traçar o quadro histórico da questão em termos jurisprudenciais, para compreender a assistência social no contexto atual através da análise dos casos concretos e crítica das decisões. Justifica-se por ser um tema polêmico, tanto em termos regulatórios quanto em de análise das políticas públicas pertinentes ao setor. A Assistência Social e as relações do Estado com as entidades do setor tem sido objeto de discussōes recentes, pela própria expansão do setor no país. Nesse contexto, a questão da imunidade tem sido o ponto mais sensível na relaçāo Estado-entidades assistenciais, provocando conflitos quanto à regulação do instituto, agravado em razão de legislação inadequada criada para o setor. A determinação dos limites da aplicação das normas de imunidade tributária das entidades assistenciais se justificaria por trazer maior segurança jurídica à área, beneficiando não somente o Estado, mas as entidades sérias do setor. A relevância teórica das discussões sobre os limites da legislação reguladora apresenta-se pela falta de padrões normativos definidos a respeito da atuação das instituiçōes, que devem ser analisadas a partir da Constituição Federal de 1988. A discussão do papel do Estado também se destaca aqui, através do estudo das relações entre este e os particulares, quando realizam atividades de interesse público. Também é relevante a análise do impacto das alterações constitucionais em matéria de regulação da assistência social, cujos conceitos ainda não se encontram adequadamente tratados nas formulações teóricas e nas decisões dos tribunais, sendo que progressivamente vão sendo incorporados, especialmente pelos tribunais. Pode-se apontar inicialmente que o Supremo Tribunal Federal historicamente oscilou em suas decisões, hora partindo de uma interpretação mais ampla e flexível, hora restringindo a aplicação da imunidade, apresentando 
recentemente a tendência à flexibilização e interpretação ampliativa em relação aos requisitos para sua configuração. Entretanto, o tratamento não é uniforme, observando-se a exemplo a restrição da aplicação da imunidade em relaçāo às Entidades de Previdência Complementar Fechadas. Verifica-se também a necessidade de uma nova legislação adequada à modernização do setor, definindo de forma mais clara as restrições à aplicação da imunidade tributária em seus vários aspectos, e adequando essas restrições aos requisitos constitucionais.

1 A Banca fol composta pelos Professores Doutores: Alvacir Alfredo Nicz, da Universidade Federal do Paraná, e Doutor em Diteito pela Universidade de São Paulo; losé Carlos Francisco, da Universidade de Săo Paulo, e Doutor em Direito pela mesma Universidade; Alcides Jorge Costa, da Universidade Presbiteriana Mackenzie, e Livre Docente em Direito pela Universidade de Sảo Paulo; Zélia Luiza Pierdona, da Universidade Presbiteriana Mackenzie, e Doutora em Direito pela Pontificia Universidade Católica de São Paulo; Carlos Klein Zanini, Professor da Universidade Federal do Rio Grande do Sul e Doutor em Direito pela Universidade de São Paulo. A referida defesa foi presidida pelo Professor Doutor Cezar Saldanha Souza Junior, da Universidade Federal do Rio Grande do Sul e Doutor em Direito pela Universidade de São Paulo, orientador do referido trabalho 


\section{A FUNÇÃO INSTRUMENTAL DAS REGRAS DE EXPERIÊNCIA NO PROCESSO CIVIL BRASILEIRO' ${ }^{1}$}

\section{GUSTAVO MARTINS DE FREITAS}

\section{Data da defesa: 27-01-2005}

\section{RESUMO}

O presente trabalho objetivou verificar a aplicabilidade das regras de experiência, a que faz menção a legislação processual brasileira, no raciocínio judicial.

Procurou-se oferecer uma visão preliminar a respeito do surgimento da doutrina da regra de experiência e sobre a importância do raciocínio indutivo na decisão judicial como fator de legitimação da utilização das mencionadas regras.

Procurou-se demonstrar os critérios mínimos a serem obedecidos para o controle da utilização de tais regras e os momentos ideais de sua aplicação. Também, como ponto essencial, foi visualizada a importância das mencionadas regras no juízo de verossimilhança.

Também foram objeto de reflexão algumas decisôes que explicitaram a utilização das regras de experiência, com a finalidade do intérprete tirar suas conclusões sobre a relevância e instrumentalidade de tais regras. Por fim, foi objeto de estudo a possibilidade de controle das regras de experiência pelo Superior Tribunal de Justiça.

\footnotetext{
I A banca foi composta pelo Professor Doutor Danilo Knijinik, Professor da Universidade Federal do Rio Grande do ul e Doutor em Direito pela Universidade de São Paulo; pelo Professor Doutor Araken de Assis, Professor da Pontificia Universidade Católica do Rio Grande do Sul, e Doutor em Direito pela Pontifícia Universidade Católica de São Paulo e pelo Professor Doutor losé Maria Rosa Tesheiner, Prótessor adjunto da Universidade Federal do Rio Grande do Sul e Livre Docente pela Universidade Federal do Rio Grande do Sul. A referida defesa foi presidida pelo Professor Doutor Carlos Alberto Alvaro de Oliveira, Professor Titular da Universidade Federal do Rio Grande do Sul, e Doutor em Direito pela Universidade de Säo Patulo, orientador do referido trabaho.
} 


\title{
EMBRIÃO HUMANO: DIRETRIZES PARA UM ESTATUTO JURÍDICO NO DIREITO PRIVADO'
}

\section{CRISTIANE AVANCINI ALVES}

\author{
Data da defesa: 06-04-2005
}

\section{RESUMO}

A presente dissertação propõe-se a analisar a qualificação jurídica do embrião humano, na medida em que a interferência dos avanços biomédicos no patrimônio genético e na identidade pessoal do ser concebido pode afetar as relaçōes jurídicas que envolvem, direta ou indiretamente, estas alterações. Será objeto de discussão a problemática relativa à atuação da manipulação genética na formação não apenas familiar, mas, também, social, e a conseqüente necessidade de se estabelecer, a priori, a delimitação jurídica do embrião humano e sua tutela. Na primeira parte seräo delineados os princípios norteadores desta proteção: responsabilidade, solidariedade e dignidade da pessoa humana, conectados entre si. Na segunda parte será; por sua vez, delineada a qualificação jurídica relativa à vida humana embrionária, bem como a análise de possíveis formas de tutela para, posteriormente, efetivar-se a proposição de um estatuto jurídico próprio ao embrião humano.

Palavras-chave: Embrião humano. Princípios. Pessoa. Personalidade. Estatuto jurídico.

\footnotetext{
1 A banca foi composta pelos Protessores Doutores: Francisco Amaral Neto, Professor da Universidade Federal do Rio de Janeiro, e Doutor em Direito pela mesma Universidade; José Roberto Goldin, Professor da Universidade Federal do Rio Grande do Sul, e Doutor em Medicina pela mesma Universidade; Cláudio F. Michelon Júnior, Professor da Universidade Federal do Rio Grande do Sul, e Doutor em Direito pela Universidade de Edimburgo, Grã-Bretanha. A referida defesa foi presidida pela Professora Doutora ludith Martins-Costa, Professora Adjunta da Universidade Federal do Rio Grande do Sul e Doutora em Direito e Livre Docente pela Universidade de Săo Paulo, orientadora do referido trabalho.
} 


\section{NATUREZA JURÍDICA DAS CONTRIBUIÇÕES NA CONSTITUIÇÃO DE $1988^{1}$}

\section{ARTHUR MARIA FERREIRA NETO}

\section{Data da defesa: 14-04-2005}

\section{RESUMO}

Esta dissertação dedica-se a identificar a natureza jurídica do tributo denominado de Contribuição pela Constituição da República Federativa do Brasil de 1988. A sua natureza jurídica será definida a partir da apreciação conjunta dos elementos essenciais extraídos diretamente do texto constitucional que podem ser ou nāo compartilhados com as demais espécies tributárias.

Palavras-chave: Tributos - Natureza Jurídica - Contribuições

\footnotetext{
A banca foi composta pelos Professores Doutores: Roberto Catalano Botelho Ferraz, Professor da Pontificia Universidade Católica do Paraná e Doutor em Direito pela Universidade de São Paulo; Ricardo Lobo Torres, Professor da Universidade do Estado do Rio de faneiro, e Doutor em Direito pela Universidade. Gama Filho; Cláudio F. Michelon lúnior, Professor da Universidade Federal do Rio Grande do Sul, e Doutor em Direito pela Universidade de Edimburgo, Grä-Bretanha. A referida defesa foi presidida pelo Professor Doutor Humberto Bergmann Ávila, Professor Doutor Humberto Bergmann Ávila, Professor Adjunto I da Universidade Federal do Rto Grande do Sul, Doutor em Direito pela Universidade de Munique Alemanha, orientador do referido trabalho.
} 


\title{
O CÓDIGO DE DEFESA DO CONSUMIDOR E O JUIZADO ESPECIAL CÍVEL NO CONTEXTO DA PÓS-MODERNIDADE ${ }^{1}$
}

\section{VERA LÚCIA REMEDI PEREIRA}

\author{
Data da defesa: 03-06-2005
}

\section{RESUMO}

Contextualizar o período em que estamos vivendo é condição para entendermos as transformaçōes ocorridas no Direito, e como o Direito se posiciona neste contexto.

O conceito de pós-modernidade está relacionado a um conjunto de mudanças sociais e culturais, representando um momento de crise sociológica, de transiçäo paradigmática entre o paradigma da modernidade e um novo paradigma. Caracteriza-se pelo descrédito nos grandes relatos legitimadores da modernidade, favorecendo a ampliação do individualismo e a busca de soluçōes individuais para resolver questôes coletivas. Está vinculado ao estágio atual do capitalismo, em vigora o neoliberalismo e a globalização.

Na medida em que o Direito reproduz a cultura pósmoderna, verificamse novas tendências, que caracterizam a cultura pós-moderna no Direito, como o pluralismo, a comunicação, a narração, o retorno dos sentimentos e a valorização dos direitos humanos.

O Código de Defesa do Consumidor e a Lei dos Juizados Especiais Cíveis representam estas novas tendências, na medida em que são microssistemas, leis especiais que favorecem a defesa do consumidor, estão relacionadas à idéia de pluralismo de fontes; a comunicação se faz através do diálogo das fontes; são normas narrativas, que descrevem valores, e são leis que favorecem a garantia de direitos humanos, uma vez que a defesa do consumidor é considerada pelo Constituiçäo Federal um direito fundamental, que necessita de uma tutela especial, sendo criado, então, o Código de Defesa do Consumidor, bem como é considerado um direito fundamental o acesso à justiça, e a Lei dos Juizados Especiais Cíveis possibilita o acesso do consumidor à jurisdição, facilitando a sua defesa em juizo.

O Direito do Consumidor é considerado o direito pós-moderno por excelência e os Juizados Especiais Cíveis representam o novo lugar da justiça no contexto da pós-modernidade.

\footnotetext{
A banca foi composta pelos Professores Doutores: Carlos Alberto Ghersi, da Universidad de Buenos Aires, Argentina, e Doutor em Direito pela Universidad Del Salvador, Buenos Aires; Célia Weingarten, da Universidad de Buenos Aires, Argentina, e Doutora em Direito pela Universidad de Buenos Aires; Maria Cristina Cereser Pezzella, da Universidade do Vale do Rio dos Sinos, e Doutora em Direito pela Universidade Federal do Paraná. A referida defesa foi presidida pela Professora Doutora Cláudia Lima Marques, Professora Titular da Universidade Federal do Rio Grande do Sul e Doutora em Direito pela Universidade de Heidelberg - Alemanha, orientadora do referido trabalno.
} 


\section{RELAÇÕES TERCEIRIZADAS DE TRABALHO'}

\section{RODRIGO COIMBRA SANTOS}

Data da defesa: 06 07-2005

\section{RESUMO}

Este trabalho estuda uma nova forma de contrato, decorrente de uma nova relação de trabalho: a relação terceirizada de trabalho, sob o ponto de vista do tratamento que lhe é dado pela jurisprudência e pela doutrina, tendo como questão central verificar se os efeitos jurídicos da fiança judicial podem ser equivalentes no plano das relaçōes terceirizadas de trabalho. Para tanto o trabalho foi dividido em quatro capítulos: 1) Relação Tradicional de Trabalho; 2) Relação Terceirizada de Trabalho; 3) Hipóteses Lícitas de Terceirização de Trabalho; e, 4) Responsabilidades na Terceirização de Trabalho.

Palavras-chave: 1. Direito do trabalho 2. Direito do trabalho - Brasil

3. Terceirização 4. Terceirização - Brasil L Título.

\footnotetext{
A banca foi composta pelos Professores Doutores: José Luiz Ferreira Prunes, da Universidade Federal do Rio Grande do Sul e Livre Docente em Direito pela mesma; Glênio José Wasserstetn Hekman, dał Universidade Federal do Rio Grande do Sul, e Doutor en Direito pela Universidade de São Paulo e Luiz Carlos Amorim Robortella, da FAAP - Fundaçăo Armando Álvares Penteado, e Doutor em Direito pela Universidade de São Pauło. A referida defesa foi presidida pelo Professor Doutor Luís Afonso Heck, Professor Adjunto da Universidade Federal do Rio Grande do Sul e Doutor em Direito Constitucional pela Universidade Federal de Minas Gerais, orientador do referido trabalho.
} 


\title{
A PROTEÇÃO AMBIENTAL NA EUROPA COMUNITÁRIA ${ }^{1}$
}

\section{LISIANE GRAVINA KUNZLER}

\author{
Data da defesa: 18-07-2005
}

\section{RESUMO}

A partir do final do século XX, ocorreu a sensibilização de determinados setores da sociedade para a necessidade da adoção de medidas efetivas propiciadoras da proteção ambiental, que garantam a preservação do meio ambiente para as gerações futuras. Neste sentido, diversos Estados e organizações internacionais passaram a perseguir este escopo. Dentro deste contexto, justifica-se o estudo do modelo de proteção ambiental adotado pela Europa comunitária. A União Européia, como entidade dotada de supranacionalidade, através de suas instituições e órgãos, procura compatibilizar a integração econômica a que se propôs inspirada na Declaração Schuman, de 1950, com a proteção ambiental, com um modelo bastante peculiar de desenvolvimento sustentável. A compreensão deste modelo pressupōe o estudo do surgimento desta proteção no âmbito comunitário, com os primeiros programas de ação em matéria ambiental, até a repartição das competências ambientais entre a União Européia e os Estados-membros, determinada pela aplicaçāo do Princípio da Subsidiariedade. O desenvolvimento do modelo europeu comunitário de proteção ambiental apóia-se na determinaçāo de objetivos comunitários a serem alcançados e nos princípios fundamentais que regem a Política Ambiental Comunitária, todos previstos nos tratados constitutivos da União Européia. A Europa comunitária, ainda, com a finalidade de alcançar seus objetivos com maior eficácia, obedece a disposições complementares, que norteiam sua atuação. Os tratados constitutivos da União Européia, revisados pelo Ato Único Europeu e pelo Tratado da União Européia, fixaram um nível de proteção ambiental elevado, determinando ainda sua integração nas demais políticas comunitárias. Ademais, os Estados-membros que adotam medidas ambientais nacionais consideradas mais rigorosas do que as estabelecidas em nível comunitário podem excepcionar a aplicação das disposiçōes comunitárias, fazendo uso da cláusula de salvaguarda, submetida ao controle comunitário. Por sua vez, as decisões tomadas pelas instituições e órgãos comunitários devem inexoravelmente considerar: os dados científicos e técnicos disponiveis; as condições do ambiente nas diversas regiōes da Comunidade; as vantagens e os encargos que podem resultar da atuação ou da ausência de atuação; e o desenvolvimento econômico e social da Comunidade no seu conjunto e o desenvolvimento equilibrado das suas regiōes. Este sistema complexo, em vigor, na Europa comunitária, na medida em que representa 
um passo sui generis na luta pela preservação ambiental, instiga e mobiliza pesquisadores do mundo inteiro.

1 A banca foi composta pelos Professores Doutores: Luis Fernando Franceschini da Rosa, da Universidade do Vale do Rio dos Sinos, e Doutor em Direito pela Universidade de Săo Paulo; Véra Maria Jacob de Fradera, da Universidade Federal do Rio Grande do Sul, e Doutora em Direito pela Universite de Paris II, França e Catherine Tinker, da Universidade Federal do Rio Grande do Sti, e Doutora em Direito pela Nova York University, EUA. A referida defesa foi presidida pela Professora Doutora Martha Lucia Olivar limenez. Professora da Universidade Federal do Rio Grande do Sul e Doutora em Direito pela Université Robert Schuman Strasbourg III, França, orientadora do referido trabalho. 


\section{AS HIPÓTESES DE ANTECIPAÇÃO DE TUTELA DO ARTIGO 273 DO CÓDIGO DE PROCESSO CIVIL ${ }^{1}$}

\section{YURI GROSSI MAGADAN}

Data da defesa: 03-08-2005

\section{RESUMO}

Há três hipóteses nas quais o juiz está autorizado a antecipar os efeitos da decisão: o perigo de dano irreparável ou de difícil reparação, o abuso no direito de defesa e a prática de atos protelatórios e, por último, a incontrovérsia total ou parcial de pedido cumulado. Para que a antecipaçäo seja deferida, devem estar presentes três requisitos: a prova inequívoca, a verossimilhança e a reversibilidade da decisão. Em qualquer das hipóteses, trata-se de juízo de verossimilhança e não de certeza. Diante da exigência legal da reversibilidade da medida, não se admite a cindibilidade do julgamento, sendo ilícito o julgamento antecipado de apenas um dos pedidos. Mesmo diante das mais recentes reformas, o legislador não alterou o sistema do julgamento único e nem criou nova hipótese de julgamento antecipado.

A banca foi composta pelos Professores Doutores: Araken de Assis, da Pontifícia Universidade Católica do Rio Grande do Sul e Doutor em Direito pela Pontificia Universidade Católica de São Paulo; Carlos Silveira Noronha, da Universidade Federal do Rio Grande do Sul, e Doutor em Direito pela Universidade de São Paulo e Ângelo Roberto llha da Silva, da Pontificia Universidade Católica do Rio Grande do Sul, e Doutor em Direito pela Universidade de Sằo Paulo. A referida defesa foi presidida pelo Professor Doutor Luis Afonso Heck, 


\section{O TELETRABALHO: UMA ANÁLISE JUSLABORAL DAS SUAS POSSIBILIDADES NA LEGISLAÇÃO BRASILEIRA ${ }^{1}$}

\section{MANUEL MARTIN PINO ESTRADA}

Data da defesa: 05-09-2005

\section{RESUMO}

Este trabalho trata sobre a análise juridica do teletrabalho tanto no Brasil, em diversos países da América Latina e no âmbito da União Européia, conceituando-o como uma forma de trabalho realizado fora da sede física da empresa ou também como aquele realizado em qualquer lugar sem vínculo empregatício, tendo à disposição os meios informáticos para o desenvolvimento do trabalho a ser feito. Salienta-se que para chegar a esta forma de trabalho que não é tão nova quanto parece houve uma evoluçāo no pensamento e na forma de trabalhar, passando da escravidão, corporações de ofício onde o aprendiz ficava em seu próprio domicílio trabalhando, quando de repente foram inventadas as máquinas a vapor e o lampião a gás que junto com a Revolução Francesa que as aboliu estes foram tirados de seus domicílios para trabalharem de forma escrava nas indústrias até que após a Revolução Industrial conquistassem os seus direitos e que conjuntamente com a evolução da tecnologia, indo da criação do chip, do computador, do microchip e da internet o trabalhador volta a trabalhar dentro de seu domicílio, tornando-se num teletrabalhador, fazendo que as empresas cada vez mais fiquem menores fisicamente, e no caso do prestador de serviço, escolher o lugar que ele quisesse para teletrabalhar, sendo um trem, um táxi dentre outras opçōes. Porém, o aspecto mais importante do teletrabalho é a oportunidade de trabalhar em vários lugares longínquos um do outro sem sair de casa.

\footnotetext{
A banca foi composta pelos Professores Doutores: José L tuiz Ferreira Prunes, da Universidade Federal do Rio Grande do Sul, e Doutor em Direilo pela mesma Universidade; Luciane Cardoso Barzotto, da Pontifícia Universidade Católica do Rio Grande do Sul, e Doutora en Direito pela Universidade Federal do Paraná; Cesar Viterbo Matos Santolim, da Universidade Federal do Rio Grande do Sul, e Doutor ern Direito pela mesma Universidade. A referida defesa foi presidida pela Professora Doutora Cláudia Lima Marques, Professora Titular da Universidade Federal do Rio Grande do Sul e Doutora em Direito pela Universidade de Heidelberg - Alemanha, orientadora do referido trabalho.
} 


\section{SEGURANÇA JURIDICA, CERTEZA DO DIREITO E TRIBUTAÇÃ̃O. A CONCRETIZAÇÃO DA CERTEZA QUANTO À INSTITUIÇÃO DE TRIBUTOS ATRAVÉS DAS GARANTIAS DA LEGALIDADE DA IRRETROATIVIDADE E DA ANTERIORIDADE ${ }^{1}$}

\section{LEANDRO PAULSEN}

Data da defesa: 21-10-2005

\section{RESUMO}

Este trabalho identifica o princípio da segurança jurídica como princípio constitucional implícito decorrente do sobreprincípio do Estado de Direito e ressalta sua particular concretização em matéria tributária, no que diz respeito ao seu conteúdo de certeza do direito, através das garantias constitucionais expressas da legalidade, da irretroatividade e das anterioridades. Aponta o alcance de cada uma dessas garantias do contribuinte constantes da Constituição brasileira de 1988, evidenciando que asseguram ao contribuinte a instituição dos tributos por lei que enseje a determinabilidade da norma, efetivamente prospectiva e conhecida com antecedência.

A banca foi composta pelos Professores Doutores: Humberto Bergmann Ávila, da Universidade Federal do Rio Grande do Sul, e Doutor em Direito pela Universidade de Munique - Alemanha; Ricardo Lobo Torres, da Universidade do Estado do Rio de Janeiro, e Livre Docente pela mesma; Marco Aurélio Greco, da Fundaçăo Getúlio Vargas/ SP, e Doutor em Direito pela Pontificia Universidade Católica de Săo Paulo. A referida defesa foi presidida pelo Professor Doutor Cezar Saldanha Souza Junior, Professor da Universidade Federal do Rio Grande do Sul e Doutor em Direito pela Universidade de Săo Paulo, orientador do referido trabalho. 